Article

\title{
An Exploratory Study of the Factors That May Affect Female Consumers' Buying Decision of Nail Polishes
}

\author{
Chen Sun ${ }^{1}$, Koushik Adhikari ${ }^{2, *}$ and Kadri Koppel ${ }^{1}$ \\ 1 Sensory Analysis Center, Kansas State University, Manhattan, KS 66502, USA; \\ E-Mails: csun@ksu.edu (C.S.); kadri@ksu.edu (K.K.) \\ 2 Food Science \& Technology, University of Georgia, Griffin, GA 30223, USA \\ * Author to whom correspondence should be addressed; E-Mail: koushik7@uga.edu; \\ Tel.: +1-770-412-4736.
}

Academic Editor: Enzo Berardesca

Received: 5 May 2015 / Accepted: 11 June 2015 / Published: 16 June 2015

\begin{abstract}
The objective of this study was to determine what factors female consumers valued more when they buy nail polish. Ninety-eight female consumers participated in a nail polish consumer study at the Sensory Analysis Center, Kansas State University. A questionnaire containing a check-all-that-apply (CATA) question, behavior questions and demographic questions was presented to each consumer. In the CATA question, the factors that may affect consumers' decision to buy a nail polish were asked, including both sensory and non-sensory factors. The frequency in percent for the factors was calculated. Sensory appeal, price and convenience of usage were the top factors that affected consumers' buying decisions. Consumers valued sensory appeal and convenience of usage; this suggested that a nail polish company's product development and advertising departments may want to focus on these two areas, primarily. The information presented in this study could help a nail polish company understand more about consumer segmentation and advertising strategy.
\end{abstract}

Keywords: nail polish; female consumers; buying decision; check-all-that-apply (CATA)

\section{Introduction}

The use of nail polish dates back to hundreds of years ago. The trend of applying nail polish first started in the society's upper class, where people mostly led a luxurious life [1]. In ancient China, people 
decorated their nails using herbal extracts and a special "lacquer". In ancient Babylon and Egypt, people colored their nails with mixtures from natural sources. Only women in the highest social order could use the dark red and crimson colors [1-3]. Records as early as the 17th and 18th centuries show European people with shiny, varnished nails [4].

The lacquer was discovered after World War I, when people were trying to make use of the nitrocellulose left from the war. Later on someone made the discovery that nitrocellulose boiled in water was soluble in organic solvents. After the solvents evaporated, the nitrocellulose became hard and glossy. Nitrocellulose was soon used as a fast-drying glossy coating in the car-paint industry [5]. Michelle Menard is generally recognized as the first person who introduced automobile paint to nail polish industry in 1920. Nail polish became one of the necessities in women's color cosmetics by the 1940s [2].

Nail polish is receiving more and more attention among consumers, today. In 2009, it was the fastest growing cosmetic category [6]. Nail polish has taken the place of lipstick as a barometer for the overall economy [7,8]. In 2011, nail polish had a global retail growth of 11\% [7]. Part of the reason for nail polish's boom is about the emerging markets. China, India, Brazil and Russia have been emerging markets in recent years, but they are also considered as "key projected growth markets" in cosmetics consumption. These countries became important to the nail polish market because their performance was crucial to nail polish industry's profit [7]. However, not only emerging markets, but developed markets, such as the US, the UK and Germany are also driving the market growth in nail polish [9]. The strong performance of developed markets helped raise the global retail value of nail polish from around $\$ 3$ billion in 2007 to more than $\$ 45$ billion in 2012 [10]. In the US alone, the nail category retail sales reached around $\$ 1$ billion in 2012 , gaining a $26 \%$ growth compared to the previous year [8].

A variety of factors affect consumers' choices of cosmetics. These factors may include sensory appeal, convenience of usage, health, season, color, age of the consumers, etc. Sensory appeal could be a major factor that contributes to consumers' choice of nail polish. "Brightening" and "illuminating" were among the most popular terms used as product claims in 2013 in UK [11]. Gloss is one of the criteria that consumers use to judge nail polish's performance. Smoothness and evenness were reported being two of the most popular terms used in nail polish market [12]. Convenience of usage could also be an important factor that affects consumers' choice. Quicker and easier to use products could attract the modern consumers who have a fast-paced life [11]. Long-lasting nail polishes could be one of the favorite claims as it could help improve the time nail polish can last without suffering from chipping and flaking, anywhere from 2-3 days to 7-10 days. Drying time, ease of maintenance and wearability could also be some other popular market claims for nail polish, and have been used as criteria to judge the performance of a nail polish by consumers [12]. Regarding the safety of nail polish, they have been shown to be microbiologically safe under test conditions [13]. Health concerns due to the chemical composition of nail polishes have been raised in recent years [14-16]. Companies have been working on new formulae/formulations to make more health- and eco-friendly nail polishes [3-5,17]. Season could be an important factor since weather condition may affect nails' condition, as well as a nail polish's quality. Some premium nail care products have been reported to tolerate the change of season, and another product is said to strengthen the nail protection from severe weather conditions [18]. Color could be one of the most important factors that affect consumers' choice. It is possible that consumers may focus more on color than brand [19].

Check-all-that-apply (CATA) method is a relatively new method where consumers check-off descriptors from a list for a product which they feel describes the product. The consumers are given a 
ballot containing descriptors/attributes that describe the product category under study and are told to check all the attributes that they think are present in a product. The results can then be related or linked to acceptability and/or buying intent [20]. An example of CATA method applied to anti-aging cream is described in the following lines. Six commercial anti-aging creams were presented to 69 consumers who received ballots with 42 descriptors in the CATA question. The categories of CATA terms included sensory descriptors, emotional descriptors, application-related descriptors, product positioning descriptors, etc. The authors concluded that CATA methodology was able to bring out the differences in samples as perceived by the consumers. They further concluded that the method was quick, and can be interpreted easily for developing marketing strategies [21].

Not much consumer insight data has been published on color cosmetics especially nail polishes. Some descriptive sensory work has been done at our lab in Kansas State University on both nail polishes and lip products $[22,23]$. The objective of this study, therefore, was to explore the factors affecting nail polish purchase by female consumers/users. A survey questionnaire containing some general questions and a CATA question on consumer habits regarding nail polishes was administered to the participants.

\section{Experimental Section}

\subsection{Consumers}

The study was approved by Kansas State University's Institutional Review Board (IRB). Ninety-eight female consumers were recruited in the Manhattan, KS area. All the consumers passed a screening questionnaire in order to qualify for the consumer study. The criteria to screen the consumers included gender, age, frequency of usage of nail polish, and fingernails/toenails questions. Consumers younger than 18 years of age were not the focus of this study, and hence were not recruited. Consumers who used nail polish less than once every three months were not selected for this study. Consumers who only applied nail polish on their toenails were also not recruited in this study.

All the questionnaires were completed online through using the data collection software Compusense at-hand (Compusense, Inc., Guelph, ON, Canada). A phone call interview was used as the screening tool to achieve a relative higher recruitment success. A general instruction about the test was also given to consumers to gauge if they qualified for this study.

\subsection{Survey Questionnaire}

The first five questions (Table 1) in the questionnaire pertained to general questions on nail polish usage. The first question in the instrument asked consumers about how often they applied nail polish. The second question and its two sub-questions asked about consumers' experience regarding nail salon visits. The third question asked where consumers usually purchased their nail polish. The options included department store, discount store, online, drug store, nail salon, and beauty supply store. The fourth and the fifth questions asked if a consumer would use a base coat or a top coat when they apply a nail polish. The sixth question (Table 2) investigated what nail polish categories consumers usually use.

The seventh question was the CATA question where each consumer was asked to select the five most important descriptors they usually consider when deciding to buy a nail polish. Twenty-four descriptors 
(Table 3) were selected based on a word frequency count from around 1000 Amazon.com reviews using NVivo (QSR International, Melbourne, Australia), which is a software for analyzing qualitative data.

Table 1. Frequency table for general questions.

\begin{tabular}{|c|c|c|c|}
\hline Q1 Frequency of Usage & Frequency & Total & Percentage \\
\hline Once a week or more & 37 & 98 & 37.8 \\
\hline Once every two weeks & 32 & 98 & 32.7 \\
\hline Once a month & 21 & 98 & 21.4 \\
\hline Once every three months & 8 & 98 & 8.2 \\
\hline Q2 Who Usually Applies Your Nail Polish & Frequency & Total & Percentage \\
\hline Self-application only & 66 & 98 & 67.3 \\
\hline Professional application only & 4 & 98 & 4.1 \\
\hline Both self and professional application & 28 & 98 & 28.6 \\
\hline Q2a Frequency of Visiting a Nail Salon & Frequency & Total & Percentage \\
\hline At least once a week & 1 & 32 & 3.1 \\
\hline Once every two weeks & 3 & 32 & 9.4 \\
\hline Once every three weeks & 5 & 32 & 15.6 \\
\hline Once a month & 8 & 32 & 25.0 \\
\hline Less than once a month & 15 & 32 & 46.9 \\
\hline Q2b Visiting a Nail Salon for Service Other Than Nail Polish Applying & Frequency & Total & Percentage \\
\hline Yes & 25 & 32 & 78.1 \\
\hline No & 7 & 32 & 21.9 \\
\hline Q3 Where to Purchase a Nail Polish? & Frequency & Total & Percentage \\
\hline Department store (JC Penny, Sears, etc.) & 14 & 98 & 14.3 \\
\hline Online & 8 & 98 & 8.2 \\
\hline Nail salon-only use nail polish without buying an extra bottle & 9 & 98 & 9.2 \\
\hline Nail salon-Either use nail polish or not and buy additional nail polish & 6 & 98 & 6.1 \\
\hline Discount store (Target, Walmart, etc.) & 89 & 98 & 90.8 \\
\hline Drug store (Walgreens, CVS Pharmacy, etc.) & 65 & 98 & 66.3 \\
\hline Beauty supply store (Sally Beauty Supply, etc.) & 41 & 98 & 41.8 \\
\hline Q4 Frequency of Usage of a Base Coat & Frequency & Total & Percentage \\
\hline Always or almost always & 28 & 98 & 28.6 \\
\hline Often but not always & 28 & 98 & 28.6 \\
\hline Occasionally but not often & 24 & 98 & 24.5 \\
\hline Rarely or never & 18 & 98 & 18.4 \\
\hline Q5 Frequency of Usage of a Top Coat & Frequency & Total & Percentage \\
\hline Always or almost always & 41 & 98 & 41.8 \\
\hline Often but not always & 26 & 98 & 26.5 \\
\hline Occasionally but not often & 17 & 98 & 17.3 \\
\hline Rarely or never & 14 & 98 & 14.3 \\
\hline
\end{tabular}


Table 2. Frequency table for nail polish category.

\begin{tabular}{ccccc}
\hline Rank & Category & Frequency & Total & Percentage (\%) \\
\hline 1 & Fast-drying & 75 & 98 & 76.5 \\
2 & Long-lasting & 71 & 98 & 72.4 \\
3 & Gel/Shellac & 24 & 98 & 24.5 \\
4 & Flakes/Glitter & 23 & 98 & 23.5 \\
5 & Water-based & 15 & 98 & 15.3 \\
6 & Other & 4 & 98 & 4.1 \\
\hline
\end{tabular}

Table 3. Frequency table for factors that may affect female consumers' decision on purchasing nail polishes.

\begin{tabular}{cccccc}
\hline Rank & Factors & Category & Frequency & Total Responses & Percentage (\%) \\
\hline 1 & Color & Sensory & 87 & 98 & 88.8 \\
2 & Price & Others & 50 & 98 & 51.0 \\
3 & Application & Sensory & 50 & 98 & 51.0 \\
4 & Coverage & Sensory & 44 & 98 & 44.9 \\
5 & Drying & Convenience of usage & 34 & 98 & 34.7 \\
6 & Long-lasting & Convenience of usage & 33 & 98 & 33.7 \\
7 & Smoothness & Sensory & 32 & 98 & 32.7 \\
8 & Maintenance & Convenience of usage & 27 & 98 & 27.6 \\
9 & Shininess & Sensory & 23 & 98 & 23.5 \\
10 & Thickness & Sensory & 20 & 98 & 20.4 \\
11 & Season & Time/Occasion & 20 & 98 & 20.4 \\
12 & Brand & Brand Related & 17 & 98 & 17.3 \\
13 & Removal & Sensory & 13 & 98 & 13.3 \\
14 & Applicator & Brand Related & 9 & 98 & 9.2 \\
15 & Occasion & Time/Occasion & 8 & 98 & 8.2 \\
16 & Health & Others & 5 & 98 & 5.1 \\
17 & Flakes & Sensory & 5 & 98 & 5.1 \\
18 & Supplies & Brand Related & 4 & 98 & 4.1 \\
19 & Aroma & Sensory & 2 & 98 & 2.0 \\
20 & Recommendations & Others & 2 & 98 & 2.0 \\
21 & Time & Time/Occasion & 2 & 98 & 2.0 \\
22 & Bottle & Brand Related & 2 & 98 & 2.0 \\
23 & Package & Brand Related & 1 & 98 & 1.0 \\
24 & Reviews & Others & 0 & 98 & 0.0 \\
\hline & & & & \\
& & & 98 & \\
\hline
\end{tabular}

\subsection{Data Analysis}

The answer frequency for the questions and their sub-questions (if applicable) was tabulated and presented as percentages. 


\section{Results and Discussion}

\subsection{General Questions}

Almost $92 \%$ of the consumers in this study painted their nails at least once a month. According to Table 1, two-thirds of the consumers chose self-application only, but no more than $5 \%$ of consumers chose professional application only. For one-third of the consumers who had experience of having nail polish applied by a professional, the majority of them visited a nail salon once a month or less. These facts indicated that home-use of nail polish is the major avenue of nail polish consumption.

Discount store, drug store and beauty supply store were the top three picked locations where consumers purchased their nail polish, whereas nail salon was the least picked location. Price, convenience and ease of access to more selections may explain the choice of the locations. Few people purchased nail polish online, and this suggested that online shopping may not have an advantage over store purchasing. The consumers did not have a clear trend regarding the application of a top or a base coat. Majority of the consumers applied both.

\subsection{Consumers' Preference for Different Categories of Nail Polishes}

As shown in Table 2, fast-drying and long-lasting were the two most frequently used nail polish products. This indicated that convenience could be one of the reasons why consumers buy nail polish. Around one-fourth of the consumers chose the Gel/Shellac and Flakes/Glitter samples. Gel/shellac samples usually cost more, and are typically sold in a nail salon. This might be the reason why consumers do not use them regularly. Water-based nail polishes were least used category in this table. The reason for this low percentage might be that consumers recruited in this study were 18 and older, and water-based nail polishes are usually advertised for children. Three out of five consumers who cared about health actually purchased the water-based nail polishes. This also suggested that water-based nail polishes could focus on consumers who think health is an important factor affecting their decisions on buying.

\subsection{Factors Affecting Consumers' Decision to Purchase a Nail Polish (CATA Data)}

As shown in Table 3, sensory factors, except for removal, flakes and aroma, were all among the top half by ranking. Color, as expected, was the most selected sensory factor when looking at the top five most important factors impacting consumers' buying decision. Almost $90 \%$ of the consumers' chose color as their single most important factor while buying nail polish. In a report by the NPD Group, Inc., it was noted that more than $60 \%$ of the consumers bought nail polish based on the color rather than the brand [19]. In fact, color is a major factor when it comes to packaging of beauty products. According to the Color Association of the United States, $85 \%$ of the consumers base their buying decisions on the color of the cosmetic packaging [24]. Price was selected as the top five important descriptors by around 50\% of the participants, which turned out to be the 2 nd most important factor for making buying decisions. It was not as high as color, and there was a big gap between color and price. Nail polish is probably not considered very expensive, and it could be used for a long time. Walker (2015) noted affordability of nail polishes was a key factor for consumers of all ages. Based on an online survey by 6000 consumers, around $70 \%$ of the consumers stated that price plays an important role in their decision to buy color cosmetics [25]. 
Coverage and ease of application had a percentage close to $50 \%$, underscoring their importance. Around $33 \%$ of the participants selected smoothness (ranked 7 out of 24 ), suggesting that the smoothness of appearance was considered important by consumers. Shininess and thickness were close to $20 \%-25 \%$. Removal was relatively low, with a percentage of $13.3 \%$, suggesting that consumers may focus on application and maintenance of the nail polish, rather than removal. Flakes and aroma were not considered important with a percentage of less than $10 \%$.

All three convenience of usage descriptors (drying, long-lasting and maintenance) ranked among the top eight most important factors, which suggested that physical properties were also important to consumers.

All the brand related factors, including brand, applicator, supplies, bottle and package were not considered important by the participants in this study. This suggested that brand information and supplies-related information may not be considered as important as the sensory, price and physical property factors to consumers.

All three time-related factors (season, occasion and time) were relatively low, compared to sensory, price and physical property factors. However, season was checked $20.4 \%$ of the times and was relatively higher than brand, which suggested that consumers may purchase products depending on seasons. According to the demographic data, 31\% consumers from the 18-30 age group, selected season as one of the top five factors. So, younger female consumers may be more willing to use different nail polishes in different seasons.

Health was not chosen by many as expected. Only $5.1 \%$ of the consumers checked health as an important factor. This might be caused by the fact that the aroma only exists during the initial application stage, and usually does not last long enough physically and in the users' memory long. Also, consumers may not use nail polish that often. Reviews were not chosen by any consumer, which indicated that not many people actually using online reviews to help them to make a decision to buy a product. Consumers do not use reviews as their source of information, probably because nail polish is a common cosmetic, and maybe there is no need for consumers to search for online reviews.

\subsection{Caveats and Future Studies}

Some cautions need to be taken when applying the results from this study. All the consumers chosen were from Manhattan, KS, USA. Studies in other locations need to be done if the results need to be applied to a broader population Health is not a major factor in purchasing a nail polish yet, but it may be something consumers will value more in the future.

\section{Conclusions}

Among all the factors that may affect consumers' decision to buy a nail polish, sensory appeal of color, price and convenience of usage are the factors valued most by consumers. Brand related factors, time or occasion, health and reviews/recommendations were not as important. When a nail polish company develops, advertises or markets a nail polish, the sensory qualities, price and convenience of usage should be major areas of focus.

Home-use is a more common way for consumers to use nail polish. This suggests that there could be potentially a bigger market in the home-use nail polish segment. For home-use nail polish consumers, 
convenience of nail polish contributes to their decisions to buy a nail polish. For example, a long-lasting product but without the need of curing might be welcomed by the consumers. Nail polish accessories are also important in nail polish product industry.

\section{Author Contributions}

This work was part of the thesis work done by Chen Sun under the guidance of Koushik Adhikari. Chen Sun designed and collected the data with guidance from Kadri Koppel and Koushik Adhikari. The first draft was written by Chen Sun which was refined by Koushik Adhikari and Kadri Koppel.

\section{Conflicts of Interest}

The authors declare no conflict of interest.

\section{References}

1. Hoobler, D.; Hoobler, T. Nail Polish. Available online: http://www.fashionencyclopedia.com/ fashion_costume_culture/Modern-World-1919-1929/Nail-Polish.html (accessed on 29 October 2014).

2. Pagano, F.C. A review of nail polish: The industrial cosmetic. Cosmet. Toilet. 2011, 126, 372-380.

3. Nail Polish. Available online: http://www.fashionencyclopedia.com/knowledge/Nail_polish.html (accessed on 28 October 2014).

4. Drahl, C. Nail polish. Chem. Eng. News 2008, 86, 42.

5. Wimmer, E.; Schlossman, M. The history of nail polish. Cosmet. Toilet. 1992, 107, 115-120.

6. Lennard, C. The Changing Hue of Color Cosmetics. GCI Magazine (April 2011). Available online: http://www.gcimagazine.com/magazine/pastissues/2011/106623458.html (accessed on 29 October 2014).

7. Walker, R. State of the Industry. GCI Magazine (June 2012). Available online: http://www. gcimagazine.com/marketstrends/regions/world/156321685.html (accessed on 29 October 2014).

8. Polla, A. The Nail Polish Effect. GCI Magazine (January 2014). Available online: http://www. gcimagazine.com/marketstrends/segments/cosmetics/The-Nail-Polish-Effect-242284221.html (accessed on 28 October 2014).

9. Explosive Growth of Nail Care Market Aided by Innovation. Available online: http://www. gcimagazine.com/marketstrends/segments/cosmetics/Professional-Nail-Care-Market-ExplodesAided-by-Product-Innovation-Kline-Reports-186973781.html?utm_source=Related+Items\&utm_ medium=website\&utm_campaign=Related+Items (accessed on 28 October 2014).

10. Walker, R. Multifunctionality: The Sweet (and Sour) Spot for Color Cosmetics. GCI Magazine (April 2013). Available online: http://www.gcimagazine.com/marketstrends/segments/cosmetics/ Multifunctionality-The-Sweet-and-Sour-Spot-for-Color-Cosmetics-199606881.html (accessed on 28 October 2014).

11. Mintel: Nail Color in UK Equals Lip Color for the First Time. Available online: http://www. gcimagazine.com/marketstrends/segments/cosmetics/Mintel-Nail-Color-in-UK-Equals-Lip-Colorfor-the-First-Time-222402441.html (accessed on 28 October 2014). 
12. Abrutyn, E.S. Deciphering Nail Polish Formulas. Available online: http://www.cosmeticsandtoiletries. com/formulating/category/color/premium-Deciphering-Nail-Polish-Formulas-214187831.html (accessed on 29 October 2014).

13. Baumgardner, C.A.; Maragos, C.S.; Walz, M.J.; Larson, E. Effects of nail polish on microbial growth of fingernails: Dispelling sacred cows. AORN J. 1993, 58, 84-88.

14. Walsh, S.A. Beyond the polish: An examination of hazardous conditions in nail salons and potential solutions for the industry in New York City. J. Law Policy 2012, 21, 243-282.

15. Houlihan, J.; Wiles, R. Beauty Secrets: Does a Common Chemical in Nail Polish Pose Risks to Human Health? Available online: http://www.ewg.org/research/beauty-secrets (accessed on 28 October 2014).

16. Chen, A.F.; Chimento, S.M.; Hu, S.; Sanchez, M.; Zaiac, M.; Tosti, A. Nail damage from gel polish manicure. J. Cosmet. Dermatol. 2012, 11, 27-29.

17. Schaefer, K. Nail Companies Revamping Ingredient List. Available online: http://www. cosmeticsandtoiletries.com/formulating/category/color/3780517.html (accessed on 29 October 2014).

18. Schaefer, K. Nail Cosmetics Get in Gear for the Changing Season. Available online: http://www. cosmeticsandtoiletries.com/formulating/category/color/4236981.html (accessed on 29 October 2014).

19. NPD Group Looks inside the Nail Care Boom. Available online: http:/www.gcimagazine.com/ marketstrends/segments/cosmetics/NPD-Group-Looks-Inside-the-Nail-Care-Boom-206421401.html? utm_source=Related+Items\&utm_medium=website\&utm_campaign=Related+Items (accessed on 28 October 2014).

20. Pensé-Lhéritier, A.M. Recent developments in the sensorial assessment of cosmetic products: A review. Int. J. Cosmet. Sci. 2015, 2015, doi:10.1111/ics.12223.

21. Parente, M.E.; Manzoni, A.V.; Ares, G. External preference mapping of commercial antiaging creams based on consumers' responses to a check-all-that-apply question. J. Sens. Stud. 2011, 26, $158-166$.

22. Sun, C.; Koppel, K.; Chambers, E. An Initial lexicon of sensory properties for nail polish. Int. J. Cosmet. Sci. 2014, 36, 262-272.

23. Dooley, L.M.; Adhikari, K.; Chambers IV, E. A general lexicon for sensory analysis of texture and appearance of lip products. J. Sens. Stud. 2009, 24, 581-600.

24. Doyle, L. The Importance of Color in Beauty Packaging. GCI Magazine (June 2014). Available online: http://www.gcimagazine.com/business/manufacturing/packaging/The-Importance-of-Color-inBeauty-Packaging-261239041.html (accessed on 4 May 2015).

25. Walker, R. The F-Word of Color Cosmetics: Functionality. GCI Magazine (February 2015). Available online: http://www.gcimagazine.com/marketstrends/segments/cosmetics/The-F-Wordof-Color-Cosmetics-Functionality-290670871.html (accessed on 4 May 2015).

(C) 2015 by the authors; licensee MDPI, Basel, Switzerland. This article is an open access article distributed under the terms and conditions of the Creative Commons Attribution license (http://creativecommons.org/licenses/by/4.0/). 